\title{
Pemodelan Resiko Kecelakaan Berbasis Kondisi Kendaraan dan Pengemudi
}

\author{
A. Putra ${ }^{\text {a }}$ dan A. Narendra ${ }^{\text {a* }}$ \\ ${ }^{a} J u r u s a n$ Teknik Sipil, Fakultas Teknik Universitas Negeri Semarang, Semarang, Indonesia \\ ${ }^{*}$ Corresponding author's e-mail: alfa.narendra@mail.unnes.ac.id
}

Received: 21 June 2021; revised: 14 July 2021; accepted: 16 July 2021

\begin{abstract}
Traffic accidents are particularly prone to occur mainly caused by vehicle speed, vehicle damage, alcohol influence, and fatigue. The study aims to model the risk of vehicle and driver-based accidents occurring across Queensland, Australia. The data in this study used a dataset of accident factors on Queensland state roads totaling 3412 accidents sourced from the Australian state government of Queensland. Research data period from 2001-2019. This research method uses multinomial logistic regression modeling analysis. The results of this study produced several models, namely; (1) Log odds in the risk level of death vs hospitalization will increase by 1,028 if affected by vehicle damage, increase by 0.731 if affected by fatigue, increase by 0.158 if affected by vehicle speed, increase by 0.151 if influenced by alcohol. (2) Log opportunities in the risk level of death vs. medical care will increase by 0.786 if affected by vehicle damage, increase by 0.375 if affected by fatigue, decrease by 0.003 if affected by vehicle speed, decrease by 0.078 if influenced by alcohol. (3) Log odds in the risk of death vs minor injury will increase by 0.484 if affected by vehicle damage, increase by 0.245 if affected by fatigue, decrease by 0.156 if affected by vehicle speed, decrease by 0.266 if influenced by alcohol. (4) Log odds in the risk of death vs property damage will increase by 1,254 if affected by vehicle damage, increase by 0.828 if affected by fatigue, increase by 0.185 if influenced by vehicle speed, increase by 0.128 if influenced by alcohol. The validation test value with crosstab method explains that the accuracy result of level 1 has an accuracy value of 0.99 and inaccuracy of 0.01 then the result of level 2 to level 5 has an accuracy value of 1 .
\end{abstract}

Keywords: traffic accidents, multinomial logistics regression, accident risk, accident factors.

Abstrak: Kecelakaan lalu lintas sangat rentan terjadi terutama yang disebabkan oleh kecepatan kendaraan, kerusakan kendaraan, pengaruh alkohol, dan kelelahan. Penelitian ini bertujuan untuk memodelkan risiko kecelakaan berbasis kendaraan dan pengemudi yang terjadi di Queensland, Australia. Data dalam penelitian ini menggunakan dataset faktor kecelakan di jalan negara bagian Queensland yang berjumlah 3412 kecelakaan bersumber dari pemerintah negara bagian Queensland, Australia. Periode data penelitian dari tahun 2001-2019. Metode penelitian ini menggunakan analisis pemodelan regresi logistik multinomial. Hasil penelitian ini menghasilkan beberapa model yaitu; (1) Peluang log dalam tingkat resiko kematian vs rawat inap akan meningkat sebesar 1.028 jika dipengaruhi kerusakan kendaraan, meningkat sebesar 0.731 jika dipengaruhi kelelahan, meningkat sebesar 0.158 jika dipengaruhi kecepatan kendaraan, meningkat sebesar 0.151 jika dipengaruhi pengaruh alkohol. (2) Peluang log dalam tingkat resiko kematian vs perawatan medis akan meningkat sebesar 0.786 jika dipengaruhi kerusakan kendaraan, meningkat sebesar 0.375 jika dipengaruhi kelelahan, menurun sebesar 0.003 jika dipengaruhi kecepatan kendaraan, menurun sebesar 0.078 jika dipengaruhi pengaruh alkohol. (3) Peluang log dalam tingkat resiko kematian vs cedera ringan akan meningkat sebesar 0.484 jika dipengaruhi kerusakan kendaraan, meningkat sebesar 0.245 jika dipengaruhi kelelahan, menurun sebesar 0.156 jika dipengaruhi kecepatan kendaraan, menurun sebesar 0.266 jika dipengaruhi pengaruh alkohol. (4) Peluang log dalam tingkat resiko kematian vs kerusakan properti akan meningkat sebesar 1.254 jika dipengaruhi kerusakan kendaraan, meningkat sebesar 0.828 jika dipengaruhi kelelahan, meningkat sebesar 0.185 jika dipengaruhi kecepatan kendaraan, meningkat sebesar 0.128 jika dipengaruhi pengaruh alkohol. Nilai uji validasi dengan metode Crosstab menjelaskan bahwa hasil akurasi level 1 memiliki nilai ketepatan 0.99 dan ketidaktepatan 0.01 kemudian hasil level 2 sampai dengan level 5 memiliki nilai ketepatan 1.

Kata kunci: kecelakaan lalu lintas, regresi logistik multinomial, resiko kecelakaan, faktor kecelakaan.

\section{Pendahuluan}

Dalam kurun waktu sembilan belas tahun dari 2001 hingga 2019, telah tercatat 3412 kasus kecelakaan di Queensland [1]. Diketahui faktor-faktor penyebab kecelakaan lalu lintas adalah kecepatan kendaraan, kerusakan kendaraan, pengaruh alkohol, dan kelelahan pengemudi [1]. Semua faktor-faktor penyebab kecelakaan lalu lintas tersebut sangat berpengaruh terhadap tingkat resiko kecelakaan.

Dari faktor-faktor penyebab kecelakaan lalulintas terhadap resiko kecelakaan ada kecenderungan perbedaan nilai yang mempengaruhi [2-6]. Penelitian ini menjelaskan jika kelelahan berpengaruh terhadapa resiko kecelakan, kelelahan itu sendiri bisa diakibatkan dari jam kerja, lama waktu mengemudi, berkendara di jalan monoton, dan mengemudi yang berkelanjutan [7-10]. Untuk pengemudi yang berkendara dipengaruhi dengan minuman alkohol meningkatkan resiko kecelakaan pada cedera dan kematian [11-12]. Faktor lain yang berpengaruh adalah kecepatan, semakin tinggi kecepatan kendaraan dalam berkendara maka frekuensi kecelakaan semakin meningkat [13].

Penelitian ini bertujuan membangun model pengaruh resiko kecelakaan yang disebabkan oleh pengemudi dan kendaraan. Model dibangun menggunakan perangkat lunak $\mathrm{R}$ dengan perintah multinomial di paket 'nnet' untuk menghasilkan model log-linear [14-15]. penelitian ini dibuat untuk bahan karya tulis ilmiah skripsi sebagai syarat meraih gelar Sarjana Teknik.

\section{Metode Penelitian}

\subsection{Jenis Penelitian}

Penelitian ini menggunakan data sekunder berupa faktor penyebab kecelakaan di Queensland, Australia pada tahun 
2001-2009 sejumlah 3412 baris data. Teknik analisis yang digunakan adalah pemodelan regresi logistik multinominal.

\subsection{Variabel Penelitian}

Variabel-variabel dalam penelitian ini teridiri dari dua variabel yaitu variabel respon (Y) dan variabel prediktor (X) seperti pada Tabel 1. Variabel respon yang dimaksud adalah resiko kecelakaan (Y) yang terdiri dari kematian (Y1/sebagai nilai referensi), rawat inap (Y2), perawatan medis (Y3), cedera ringan (Y4), dan kerusakan properti (Y5). Kemudian variabel prediktor yang digunakan sesuai data korban kecelakaan di Queensland Australia adalah faktor-faktor penyebab kecelakaan meliputi pengaruh alkohol $\left(\mathrm{X}_{1}\right)$, kecepatan kendaraan $\left(\mathrm{X}_{2}\right)$, kelelahan $\left(\mathrm{X}_{3}\right)$, dan kerusakan kendaraan $\left(\mathrm{X}_{4}\right)$.

Tabel 1. Variabel penelitian

\begin{tabular}{|c|c|}
\hline Variabel & Kategori \\
\hline \multirow{5}{*}{$\begin{array}{l}\text { Tingkat Resiko } \\
\text { Kecelakaan (Y) }\end{array}$} & $1=$ Kematian $/$ fatal \\
\hline & $2=$ Rawat Inap \\
\hline & $3=$ Perawatan Medis \\
\hline & $4=$ Cedera Ringan \\
\hline & $5=$ Kerusakan Properti \\
\hline \multirow{2}{*}{ Pengaruh Alkohol $\left(\mathrm{X}_{1}\right)$} & $1=$ Yes \\
\hline & $2=\mathrm{No}$ \\
\hline \multirow{2}{*}{ Kecepatan Kendaraan $\left(\mathrm{X}_{2}\right)$} & $1=$ Yes \\
\hline & $2=\mathrm{No}$ \\
\hline \multirow{2}{*}{ Kelelahan $\left(\mathrm{X}_{3}\right)$} & $1=$ Yes \\
\hline & $2=\mathrm{No}$ \\
\hline \multirow{2}{*}{ Kerusakan Kendaraan $\left(\mathrm{X}_{4}\right)$} & $1=$ Yes \\
\hline & $2=\mathrm{No}$ \\
\hline
\end{tabular}

\subsection{Metode dan Tahapan Penelitian}

Prosedur dalam menganalisis data pada penelitian ini adalah sebagai berikut:

1) Melakukan analisis deskriptif data kualitatif untuk mengetahui karakteristik kecelakaan lalu lintas di Queensland Australia, tahun 2001-2019.

2) Menguji independensi data pada variabel prediktor dengan variabel respon masing-masing.

3) Menyusun model menggunakan metode analisis regresi logistik multinomial dengan langkah-langkah sebagai berikut:

a) Melakukan estimasi parameter untuk mengetahui pengaruh variabel respon terhadap masing-masing variabel prediktor.

b) Membentuk fungsi logit pada masing-masing kategori variabel respon di setiap model pada tabel estimasi parameter.

c) Melakukan uji simultan untuk mengetahui variabel prediktor yang mempunyai hubungan terhadap variabel respon secara bersama-sama.

d) Melakukan uji parsial untuk mengetahui variabel prediktor yang mempunyai hubungan terhadap variabel respon secara sebagian.

e) Intepretasi oods ratio untuk mengetahui model terbaik berdasarkan kontribusi variabel prediktor yang berpengaruh terhadap variabel respon pada masing-masing model. f) Menghitung validasi model untuk mengevaluasi model berdasarkan data dan prediksi.

g) Menghitung ketepatan klasifikasi model.

h) Membuat kesimpulan dan saran dari analisis hasil data.

\section{Hasil dan Pembahasan}

\subsection{Analisis Deskriptif Variabel Penelitian}

Analisis deskriptif yang berupa data kualitatif ini dilakukan bertujuan untuk mengidentifikasi gambaran atau sebaran data sehingga menghasilkan informasi yang jelas. Deskripsi data disajikan pada Tabel 2.

Tabel 2. Deskripsi data

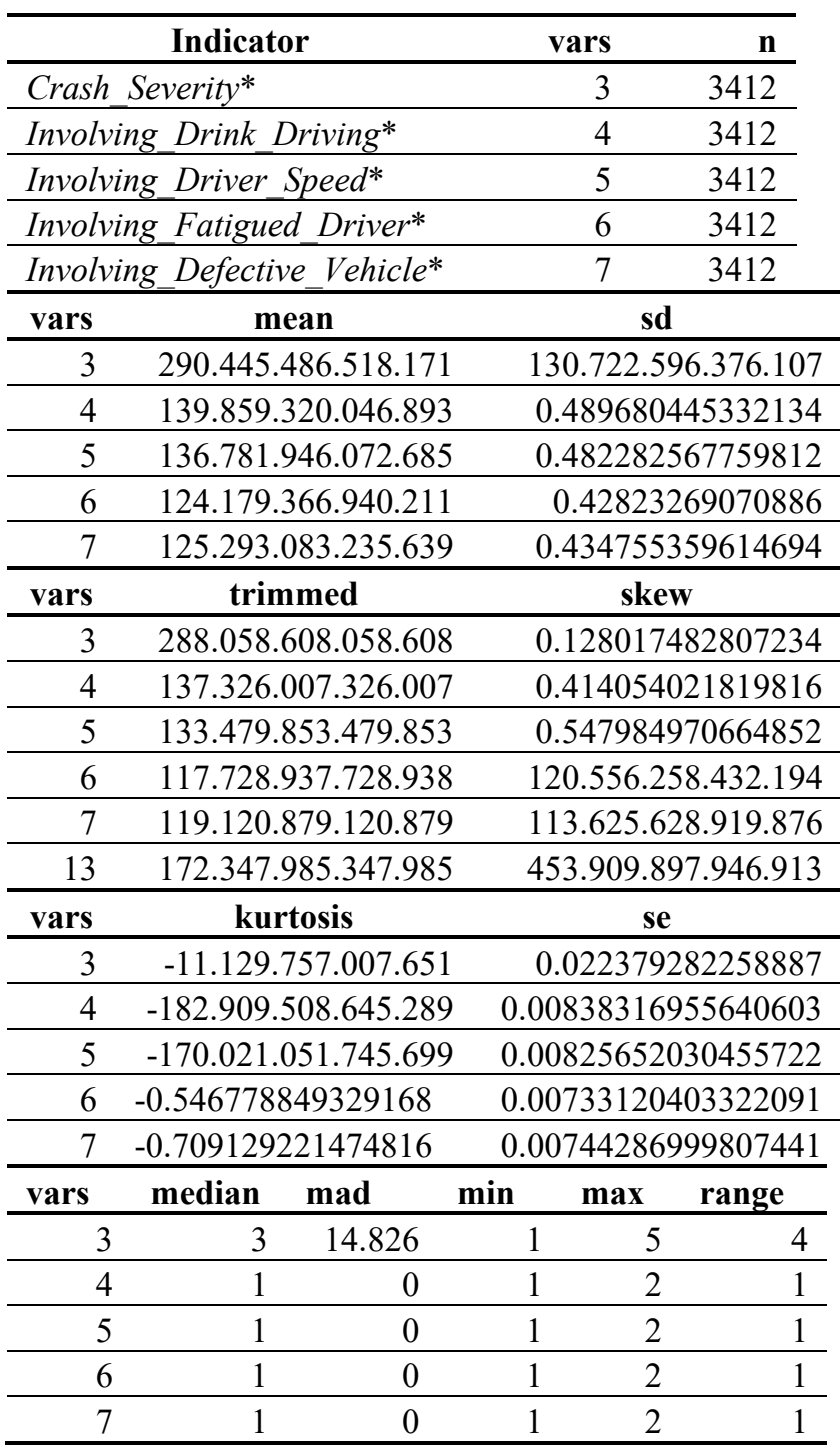

Dalam penelitian ini, analisis yang disajikan yaitu variabel respon resiko kecelakaan lalu lintas di Queensland Australia dan variabel prediktor antara lain variabel minuman alkohol $\left(\mathrm{X}_{1}\right)$, kecepatan kendaraan $\left(\mathrm{X}_{2}\right)$, kelelahan $\left(\mathrm{X}_{3}\right)$, dan kerusakan kendaraan $\left(\mathrm{X}_{4}\right)$. Dengan data penelitian sejumlah 3412 dan jumlah 4303 korban kecelakaan. Nomor variabel (vars) mengikuti nomor kolom dari file dataset 


\subsection{Uji Korelasi}

Uji korelasi dilakukan dengan menggunakan paket psych dalam perangkat lunak $\mathrm{R}$, dengan perintah pairs.panels. Pairs.panels menunjukkan matriks scatter plot (scatter plot of matrices (SPLOM)), dengan plot scatter bivariate dibawah diagonal, histogram di diagonal, dan korelasi Pearson diatas diagonal.
Berdasarkan Gambar 1, dapat dilihat variabel resiko kecelakaan lalu lintas (secara umum) tidak memiliki korelasi yang kuat dengan variabel-variabel lain. Begitu pula antar variabel yang lain. Hal ini menunjukkan tidak adanya multicollinearity, sehingga dari data tersebut bisa dibangun model dengan seluruh variabel yang ada.


Gambar 1. Uji korespondensi

\subsection{Pemodelan Regresi Logistik Multinomial}

1) Estimasi Parameter

Pemodelan regresi logistik multinomial untuk penelitian ini menggunakan metode maximum likelihood estimation dimana prinsip utama maksimum likelihood adalah mencari $\beta$ yang dapat memaksimumkan fungsi likelihood.

Tabel 3. Estimate parameter

Summary model multinomial data Factors in road crashes

Call:

multinom(formula $=$ Crash_Severity

Involving_Drink_Driving + Involving_Driver_Speed + Involving_Fatigued_Driver + Involving_Defective_Vehicle, data $=$ dataku)

Coefficients:

$\begin{array}{lcl} & & \text { (Intercept) } \\ \text { Hospitalisation } & -0.0756461 & \text { (B10) } \\ \text { Medical treatment } & 0.1004481 & \text { (B } 10) \\ \text { Minor injury } & 0.1994509 & \text { (B } 30) \\ \text { Property damage only } & -0.7282121 \text { (B40) }\end{array}$

Involving_Drink_DrivingYes Hospitalisation 0.15147591

Medical treatment $\quad-0.07776278$

Minor injury $\quad-0.26644147$

Property damage only
Lanjutan Tabel 3. Estimate parameter

\begin{tabular}{llll}
\hline Involving_Driver_SpeedYes & (X2) & \\
Hospitalisation 0.158365205 & (B12) & \\
Medical treatment & -0.003440055 & (B22) \\
Minor injury & -0.155757221 & (B32) \\
Property damage only & 0.185284313 & (B42)
\end{tabular}

Involving_Fatigued_DriverYes (X3)

Hospitalisation 0.7298788

Medical treatment $\quad 0.3752683$

Minor injury $\quad 0.2453892$

Property damage only $\quad 0.8275117$

(B23)

Involving_Defective_VehicleYes (X4)

Hospitalisation 1.0282871

Medical treatment $\quad 0.7863517$

Minor injury $\quad 0.4835910$

(B24)

Property damage only $\quad 1.2536728$

(B34)

Std. Errors: $\quad$ (Intercept)

Hospitalisation 0.109367

Medical treatment $\quad 0.1083478$

Minor injury $\quad 0.1084473$

Property damage only $\quad 0.1283911$

Involving_Drink_DrivingYes

Hospitalisation 0.1120308

Medical treatment $\quad 0.1151319$

Minor injury $\quad 0.1190242$

Property damage only $\quad 0.1281609$ 
Lanjutan Tabel 3. Estimate parameter

Involving_Driver SpeedYes

Hospitalisation 0.1163405

Medical treatment $\quad 0.1189915$

Minor injury $\quad 0.1228722$

Property damage only $\quad 0.13282$

Involving_Fatigued_DriverYes

Hospitalisation 0.1405002

Medical treatment $\quad 0.1455458$

Minor injury $\quad 0.1487147$

Property damage only $\quad 0.1590068$

Involving_Defective_VehicleYes

Hospitalisation 0.1467726

Medical treatment $\quad 0.1496835$

Minor injury $\quad 0.1556652$

Property damage only $\quad 0.1611397$

$\begin{array}{ll}\text { Weights : : } & 30(20 \text { variabel }) \\ \text { initial value } & 5491.402157 \\ \text { iter } 10 \text { value } & 5384.186598 \\ \text { iter } 10 \text { value } & 5367.800790 \\ \text { final value } & 5363.888063 \\ \text { Convereged } & \end{array}$

Sumber: hasil analisa regeresi logistik multinomial

Hasil nilai estimasi parameter berdasarkan Tabel 3, dapat dituliskan model regresi logistik multinomial dengan kematian $(\mathrm{Y}=1)$ adalah nilai referensi sebagai berikut :

- Fungsi logit 1 untuk resiko kecelakaan rawat inap $\ln \left[\frac{P(\text { crash saverity=hospitalisation })}{P(\text { crash savereity }=\text { fatal })}\right]=\mathrm{B} 10+\mathrm{B} 11\left(\mathrm{x}_{1}\right)+$ $\mathrm{B} 12\left(\mathrm{x}_{2}\right)+\mathrm{B} 13\left(\mathrm{x}_{3}\right)+\mathrm{B} 14\left(\mathrm{x}_{4}\right)$

- Fungsi logit 2 untuk resiko kecelakaan perawatan medis

$$
\begin{aligned}
& \ln \left[\frac{P(\text { crash saverity }=\text { medical treatment })}{P(\text { crash saverity }=\text { fatal })}\right]=\mathrm{B} 20+ \\
& \mathrm{B} 21\left(\mathrm{x}_{1}\right)-\mathrm{B} 22\left(\mathrm{x}_{2}\right)+\mathrm{B} 23\left(\mathrm{x}_{3}\right)+\mathrm{B} 24\left(\mathrm{x}_{4}\right)
\end{aligned}
$$

- Fungsi logit 3 untuk resiko kecelakaan cedera ringan $\ln \left[\frac{P(\text { crash saverity }=\text { minor in jury })}{P(\text { crash saverity }=\text { fatal })}\right]=\mathrm{B} 30+\mathrm{B} 31\left(\mathrm{x}_{1}\right)+$ $\mathrm{B} 32\left(\mathrm{x}_{2}\right)+\mathrm{B} 33\left(\mathrm{x}_{3}\right)+\mathrm{B} 34\left(\mathrm{x}_{4}\right)$

- Fungsi logit 4 untuk resiko kecelakaan kerusakan properti

$\begin{aligned} & \ln \left[\frac{P(\text { crash saverity= property damage only })}{P(\text { crash saverity }=\text { fatal })}\right] \\ & \mathrm{B} 41\left(\mathrm{x}_{1}\right)+\mathrm{B} 42\left(\mathrm{x}_{2}\right)+\mathrm{B} 43\left(\mathrm{x}_{3}\right)+\mathrm{B} 44\left(\mathrm{x}_{4}\right)\end{aligned}=\mathrm{B} 40+$

Berdasarkan model tersebut maka dapat di jelaskan seperti pada Tabel 4.

Tabel 4. Hubungan resiko kecelakaan

\begin{tabular}{ccccc}
\hline & $(\mathrm{X} 4)$ & $(\mathrm{X} 3)$ & $(\mathrm{X} 2)$ & $(\mathrm{X} 1)$ \\
\hline Y1 vs Y2 & +1.028 & +0.731 & +0.158 & +0.151 \\
\hline Y1 vs Y3 & +0.786 & +0.375 & -0.003 & +0.078 \\
\hline Y1 vs Y4 & +0.484 & +0.245 & -0.156 & -0.266 \\
\hline Y1 vs Y5 & +1.254 & +0.828 & +0.185 & +0.128 \\
\hline
\end{tabular}

Keterangan : $(+)=$ meningkat; $(-)=$ menurun

Berdasarkan Tabel 4, menjelaskan bahwa tanpa variabel independen (intercept only) nilainya 5491.402157 sedangkan dengan memasukan variabel independen ke model (final) terjadi penurunan nilai menjadi 5363.888063. Perubahan ini menunjukan minimal ada satu variabel bebas yang berpengaruh terhadap variabel respon yang berarti model cocok dengan data.

2) Intepretasi Odds Ratio

Pada model regresi logistik yang digunakan untuk intepretasi koefisien adalah odds ratio (Tabel 5). Nilai odds ratio merupakan rasio probabilitas memilih satu kategori atas kemungkinan memilih nilai referensi kategori yang disebut sebagai risiko relatif.

Tabel 5. Oods ratio

Dependent variable:

Hospitalisation Medical treatment

(1) (2)

Minor injury Property damage only

(3)

(4)

Involving_Drink_DrivingYes

$\begin{array}{llllll}1.164 & 0.925 & 0.766 * * & 1.136 & (0.112) & (0.115)\end{array}$

(0.119) (0.128)

Involving_Driver_SpeedYes

$\begin{array}{llll}1.172 & 0.997 & 0.856 & 1.204\end{array}$

$\begin{array}{llll}(0.116) & (0.119) & (0.123) & (0.133)\end{array}$

Involving_Fatigued_DriverYes

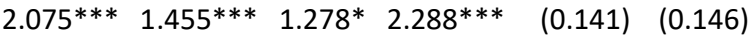

(0.149) (0.159)

Involving_Defective_VehicleYes

$\begin{array}{lllll}2.796^{* * *} & 2.195^{* * *} & 1.622^{* * *} 3.503^{* * *} & (0.147) & (0.150)\end{array}$

(0.156) (0.161)

Constant

$0.927 \quad 1.1061 .221 * 0.483 * * * \quad(0.109) \quad(0.108)$

(0.108) (0.128)

Akaike Inf. Crit.

10,767.780 10,767.780 10,767.780 10,767.780

Note: $\quad{ }^{*} \mathrm{p}<0.1 ;{ }^{* *} \mathrm{p}<0.05 ;{ }^{* * *} \mathrm{p}<0.01$

Sumber: Hasil analisa resiko relative

Berdasarkan Tabel 6 maka dapat dijelaskan sebagai berikut:

- Rasio risiko relatif untuk peningkatan satu unit variabel kelelahan adalah 0.141 dan variabel kerusakan kendaraan adalah 0.147 pada kematian vs rawat inap

- Rasio risiko relatif untuk peningkatan satu unit variabel kelelahan adalah 0.146 dan variabel kerusakan kendaraan 0.150 pada kematian vs perawatan medis

- Rasio risiko relatif untuk peningkatan satu unit variabel pengaruh minuman adalah 0.119 , variabel kelelahan adalah0.149, dan variabel kerusakan kendaraan adalah 0.156 pada kematian vs cedera ringan

- Rasio resiko relatif untuk peningkatan satu unit variabel kelelahan adalah 0.159 dan variabel kerusakan kendaraan adalah 0.161 pada kematian vs kerusakan properti. 
REKOnSTRUKSI TADULAKO: Civil Engineering Journal on Research and Development, Vol. 2(2), September 2021

3) Uji Validasi (ketetapan klasifikasi model)

Tabel 6a dan Tabel 6b, menjelaskan data sebesar $39,86 \%$ dipengaruhi alkohol, 36,78\% dipengaruhi kecepatan kendaraan, 24,18\% dipengaruhi kelelahan pengemudi, dan 25,29\% dipengaruhi kerusakan kendaraan

Tabel 6a. Uji keseusaian model untuk X1 dan X2

\begin{tabular}{lrrrrrr}
\hline \multirow{2}{*}{$Y$} & \multicolumn{2}{c}{ X1 } & \multirow{2}{*}{$\%$} & \multicolumn{2}{c}{ X2 } & \multirow{2}{*}{$\%$} \\
\cline { 2 - 3 } & NO & YES & correct & NO & YES & correct \\
\hline Y1 & 323 & 245 & 43,13 & 346 & 222 & 39,08 \\
\hline Y2 & 509 & 374 & 42,36 & 550 & 333 & 37,71 \\
\hline Y3 & 478 & 296 & 38,24 & 494 & 280 & 36,18 \\
\hline Y4 & 442 & 239 & 35,1 & 451 & 230 & 33,77 \\
\hline Y5 & 300 & 206 & 40,71 & 316 & 190 & 37,55 \\
\hline Jumlah & 2052 & 1360 & & 2157 & 1255 & \\
\hline overall \% & 60,14 & 39,86 & & 63,22 & 36,78 & \\
\hline
\end{tabular}

Tabel 6b. Uji keseusaian model untuk X3 dan X4

\begin{tabular}{|c|c|c|c|c|c|c|}
\hline \multirow[t]{2}{*}{$\bar{Y}$} & \multicolumn{2}{|c|}{ X3 } & \multirow{2}{*}{$\begin{array}{c}\% \\
\text { correct }\end{array}$} & \multicolumn{2}{|c|}{$\mathrm{X4}$} & \multirow{2}{*}{$\begin{array}{c}\% \\
\text { correct }\end{array}$} \\
\hline & NO & $\overline{\text { YES }}$ & & NO & $\overline{\text { YES }}$ & \\
\hline $\bar{Y} 1$ & 457 & 111 & 19,54 & 482 & 86 & $\overline{15,14}$ \\
\hline Y2 & 643 & 240 & 27,18 & 632 & 251 & 28,43 \\
\hline Y3 & 596 & 178 & 23,00 & 567 & 207 & 26,74 \\
\hline Y4 & 524 & 157 & 23,05 & 527 & 154 & 22,61 \\
\hline Y5 & 367 & 139 & 27,47 & 341 & 165 & 32,61 \\
\hline Jumlah & 2587 & 825 & & 2549 & 863 & \\
\hline overall $\%$ & 75,82 & 24,18 & & 74,71 & 25,29 & \\
\hline
\end{tabular}

Suber: hasil analisa pengolahan tabulasi data

Pada pengujian validasi ini dilakukan penggunaan model terhadap data train dan data test. Untuk kemudian hasilnya disajikan dengan metode Cross Tab. Pembagian penggunaan data sebagai berikut, $70 \%$ data untuk data training dan sisanya untuk data testing.

Tabel 7. Hasil Uji Validasi Model

\begin{tabular}{|c|c|c|c|c|c|}
\hline Populasi & 1 & 2 & 3 & 4 & 5 \\
\hline 1 & 166 & 1 & 0 & 0 & 0 \\
\hline 2 & 0 & 259 & 0 & 0 & 0 \\
\hline 3 & 0 & 0 & 232 & 0 & 0 \\
\hline 4 & 0 & 0 & 0 & 204 & 0 \\
\hline 5 & 0 & 0 & 0 & 0 & 162 \\
\hline
\end{tabular}

Sumber: hasil Analisa data data dan prediksi

Berdasarkan Tabel 7 menjelaskan bahwa hasil akurasi level 1 memiliki nilai ketepatan 0.99 dan ketidaktepatan 0.01 kemudian hasil level 2 sampai dengan level 5 memiliki nilai ketepatan 1. Dari hasil prdediksi tersebut maka model fungsi logit dapat ditetapkan untuk memodelkan tingkat resiko kecelakaan lalu lintas di Australia.

\section{Kesimpulan}

Berdasarkan analisis hasil dan pembahasan maka di dapat kesimpulansebagai berikut:
1) Beberapa model terbaik tingkat resiko kecelakan lalu lintas dengan kategori masing-masing:

- Fungsi logit 1 untuk resiko kecelakaan rawat inap $\ln \left[\frac{P(\text { crash saverity }=\text { hospitalisation })}{P(\text { crash savereity }=\text { fatal })}\right]=\mathrm{B} 10+\mathrm{B} 11\left(\mathrm{x}_{1}\right)+$ $\mathrm{B} 12\left(\mathrm{x}_{2}\right)+\mathrm{B} 3\left(\mathrm{x}_{3}\right)+\mathrm{B} 4\left(\mathrm{x}_{4}\right)$

- Fungsi logit 2 untuk resiko kecelakaan perawatan medis

$\ln \left[\frac{P(\text { crash saverity }=\text { medical treatment })}{P(\text { crash saverity }=\text { fatal })}\right]=\mathrm{B} 20+$ $\mathrm{B} 21\left(\mathrm{x}_{1}\right)-\mathrm{B} 22\left(\mathrm{x}_{2}\right)+\mathrm{B} 23\left(\mathrm{x}_{3}\right)+\mathrm{B} 24\left(\mathrm{x}_{4}\right)$

- Fungsi logit 3 untuk resiko kecelakaan cedera ringan $\ln \left[\frac{P(\text { crash saverity }=\text { minor injury })}{P(\text { crash saverity }=\text { fatal })}\right]=\mathrm{B} 30+\mathrm{B} 31\left(\mathrm{x}_{1}\right)+$ $\mathrm{B} 32\left(\mathrm{x}_{2}\right)+\mathrm{B} 33\left(\mathrm{x}_{3}\right)+\mathrm{B} 34\left(\mathrm{x}_{4}\right)$

- Fungsi logit 4 untuk resiko kecelakaan kerusakan properti

$$
\begin{aligned}
& \ln \left[\frac{P(\text { crash saverity }=\text { property damage only })}{P(\text { crash saverity }=\text { fatal })}\right]=\mathrm{B} 40+ \\
& \mathrm{B} 41\left(\mathrm{x}_{1}\right)+\mathrm{B} 42\left(\mathrm{x}_{2}\right)+\mathrm{B} 43\left(\mathrm{x}_{3}\right)+\mathrm{B} 44\left(\mathrm{x}_{4}\right)
\end{aligned}
$$

2) Rasio risiko relatif untuk peningkatan satu unit variabel kelelahan adalah 0.141 dan variabel kerusakan kendaraan adalah 0.147 pada kematian vs rawat inap. Rasio risiko relatif untuk peningkatan satu unit variabel kelelahan adalah 0.146 dan variabel kerusakan kendaraan 0.150 pada kematian vs perawatan medis. Rasio risiko relatif untuk peningkatan satu unit variabel pengaruh minuman adalah 0.119 , variabel kelelahan adalah 0.149 , dan variabel kerusakan kendaraan adalah 0.156 pada kematian vs cedera ringan. Rasio resiko relatif untuk peningkatan satu unit variabel kelelahan adalah 0.159 dan variabel kerusakan kendaraan adalah 0.161 pada kematian vs kerusakan properti.

3) Berdasarkan hasil data tabulasi menjelaskan data sebesar $39,86 \%$ dipengaruhi alkohol, 36,78\% dipengaruhi kecepatan kendaraan, 24,18\% dipengaruhi kelelahan pengemudi, dan $25,29 \%$ dipengaruhi kerusakan kendaraan.

4) Nilai uji validasi atau ketetapan klasifikasi model dengan metode cross tab menjelaskan bahwa hasil akurasi data vs prediksi level 1 memiliki nilai ketepatan 0.99 dan ketidaktepatan 0.01 kemudian hasil data vs prediksi level 2 sampai dengan level 5 memiliki nilai ketepatan 1.

\section{Daftar Pustaka}

[1] https://www.data.qld.gov.au/dataset/crash-data-fromqueensland-roads (diakses tanggal 29 Maret 2021)

[2] E.S. Hutabarat, "Analisa Potensi Resiko Keselamatan Pengemudi Barang Bahan Berbahaya dan Beracun Berdasarkan Agreement for Transport of Dangerous Goods by Road (ADR)", Jurnal Penelitian Transportasi Darat, vol. 21, no. 2, p. 125, 2019. 
[3] L.A. Nugroho, H. Sulistio, and A. Kusuma, "Karakteristik Pengemudi dan Model Peluang Terjadinya Kecelakaan Bus Antar Kota Antar Propinsi”, Jurnal Rekayasa Sipil, vol. 6, no. 1, p. 42, 2012.

[4] D.G.N. da Costa, "Analisis Resiko Kecelakaan Pengguna Sepeda Motor, International Symposium of the Indonesian inter University Transport Studies", vol. 15, p. 1, 2012.

[5] T. Permanawati, H. Sulistio, and A. Wicaksono, "Model Peluang Kecelakaan Sepeda Motor Berdasarkan Karakteristik Pengendara (Studi Kasus: Surabaya, Malang dan Sragen)", Jurnal Rekayasa Sipil, vol. 4, no. 3, p. 186, 2010.

[6] B. Haryadi, "Eksplorasi Model Tingkat Kecelakaan Lalu Lintas", Jurnal Teknik Sipil dan Perencanaan, vol. 13, no. 1, p. 2013.

[7] F. Wensheng and X. Jianping, "Study on Risk Factors for Transport Crashes Involving Fatigued Professional Drivers", Advanced Materials Research, vol. 790, p. 458, 2013.

[8] L.A. Rakhmat, A. Kusumawati, R.B, Frazila, and S. Hendarto, "Pengembangan Model Prediksi Kecelakaan Lalu Lintas pada Jalan Tol Purbaleunyi", Jurnal Teknik Sipil, vol. 19, no. 3, p. 277, 2012.

[9] V.D. Fridayanti and D. Prasetyanto, "Model Hubungan antara Angka Korban Kecelakaan Lalu Lintas dan Faktor Penyebab Kecelakaan pada Jalan Tol Purbaleunyi”, RekaRacana: Jurnal Teknil Sipil, vol. 5, no. 2, p. 124, 2019.
[10] W. Wesli, "Pengaruh Pengetahuan Berkendaraan Terhadap Perilaku Pengendara Sepeda Motor Menggunakan Structural Equation Model (SEM)", Teras Jurnal, vol. 5, no. 2, p. 43, 2015.

[11] W.N. Venables and B.D. Ripley, Statistic and Somputing (Edisi ke-4), New York: Springer Science Business, 2002.

[12] Miranti, F.Y. Rumlawang, F. Kondolembang, "Pemodelan Faktor -Faktor Penyebab Keparahan Korban Kecelakaan Lalu Lintas di Kota Ambon Dengan Menggunakan Model Regresi Logistik Multinomial", Variance, vol. 1, no. 1, p. 17, 2019.

[13] M.C. Taylor, D.A. Lynam, and A. Baruya, The Effects of Driver's Speed on the Frequency of Road Accidents (TRL Report 421), Crowthorne: Transport Research Laboratory, 2000.

[14] https://media.readthedocs.org/pdf/little-book-of-r-formultivariate-analysis/latest/little-book-of-r-formultivariate-analysis.pdf (diakses pada tanggal 09 Maret 2021)

[15] http://cran.r-project.org/web/packages/nnet/nnet.pdf (diakses pada tanggal 08 April 2021) 